\title{
Retinopathy of Prematurity in Babies Born of Infertility Treatment- Cradle ROP Experience
}

\section{Manoj Soman, Sameer I*, Anshuman Gahlot, Sheera K R, Abdul Nizar $A P$ and Unnikrishnan Nair $R$}

Chaithanya Eye Hospital and Research Institute, Thiruvananthapuram, Kerala, India

*Corresponding Author: Sameer I, Department of Vitreo-Retinal Service, Chaithanya Eye Hospital and Research Institute, Thiruvananthapuram, Kerala, India.
Received: August 10, 2021

Published: August 21, 2021

(C) All rights are reserved by Sameer I., et al.

\begin{abstract}
Purpose: To examine the incidence of Retinopathy of Prematurity (ROP) in children conceived through assisted reproductive techniques (ART) and to analyze whether the severity of ROP varied with babies born through natural conception.

Methods: This was a retrospective chart analysis of the CRADLE ROP data between September 2018 and April 2020 and included a multicentric NICU based neonatal screening for Retinopathy of Prematurity using the mobile Retcam Imaging system. Birth weight, gestational age, time of first examination, presence or absence of any stage of ROP, severity of the disease especially APROP and treatment were analyzed. Babies born through natural conception were compared with ART born babies.

Results: 492 Neonates were examined during this period. ROP was detected in $22.7 \%$ and treatment for ROP was advised in $21.4 \%$ neonates who developed ROP. 34 infants (6.9\%) were born through assisted conception. Infants born through assisted conception accounted for $25 \%$ of all those infants requiring treatment. Out of those born through natural conception $22 \%$ (101 babies) developed ROP and $17.8 \%$ of these needed treatment. 32\% (11 babies) of ART born babies developed ROP and 54\% (6 babies) of these needed treatment. Bilateral APROP requiring anti-VEGF treatment was seen in $9 \%$ babies in the ART group compared to $1.9 \%$ in the other group. ROP that developed in ART babies were more in need of treatment than natural conception [OR - 5.33 (95\% CI: 1.54, 18.47) with p-value $<0.05]$.

Conclusion: ART born babies make up a considerable proportion of the ROP babies who need treatment. Therefore, increased vigilance is required when screening babies conceived by assisted conception. With the demand for infertility treatment and use of assisted conception increasing, it can only be expected that this number will increase in future.
\end{abstract}

Keywords: Retinopathy of Prematurity (ROP); Assisted Reproductive Techniques (ART)

\section{Introduction and Aim of Study}

Retinopathy of prematurity (ROP) is a complex disease of the retina with a multi-factorial etiology and an early intervention has been observed to prevent irreversible vision loss in some of these prematurely born infants [1]. ROP remains as a major cause of blindness in premature infants and the incidence is increased along with the elevated survival of infants born at very early gestational ages $[2,3]$. The World Health Organization estimates that more than 15 million preterm neonates are born annually and that with the increase in the survival rate, the incidence of ROP will also rise. Therefore, there is a need for timely diagnosis and treatment of ROP patients [4]. Short gestation and low birth weight have been identified as the most important risk factors responsible for ROP and other recognized risk factors being sepsis, intraventricular hemorrhage (IVH), mechanical ventilation, oxygen therapy, blood transfusion and exposure to light [5]. Recently, a rise in the number of children admitted to Neonatal Intensive Care Units (NICUs) 
across India has been observed with an increase in the number of preterm babies with ROP due to variable neonatal practices [6]. This emerging epidemic of ROP blindness is the result of high birth rate, high rate of preterm births, increased number and survival of low birth weight children due to the advanced assisted reproductive techniques and expanded provision of medical care [7].

Assisted reproductive technique (ART) has grown in the last few years. It is now being increasingly available to infertile couples in both developed and developing countries. Initially considered a taboo, many infertile couples are now proactive in opting for ART treatment. As multiple pregnancies are common in assisted conception an increase in the number of preterm and low birth weight babies is recently evident. A study in India on Assisted reproductive techniques found $22 \%$ of such gestations to be having twins [8]. Reports of impact of ART on incidence or progression of ROP have been inconsistent in the past. Some studies found associations between ART and ROP, whereas others suggest the contrary [9-13]. Given the lack of consistency in the published data, and paucity of such studies from India, we looked at the role of ART in the development of ROP and its treatment in neonatal intensive care setting.

\section{Materials and Methods}

Institutional review board approval was obtained for review of data for the study. This was a retrospective chart analysis of the CRADLE ROP data between September 2018 and April 2020 and included multicentric NICU born neonates who were screened for Retinopathy of Prematurity using the mobile Retcam Imaging system, according to the ROP screening criteria by National Neonatology Forum (NNF) of India. The CRADLE ROP is an initiative of the Chaithanya Sight Foundation aimed at offering ROP screening and treatment at the NICU set up and works in coordination with local neonatologists. Birth weight in grams, gestational age in weeks, time of first examination, presence and number of multiple simultaneous gestations, presence or absence of any stage of ROP, severity of the disease especially APROP, details of ROP treatment with laser or intravitreal Anti-VEGF injection were analyzed. Responses with respect to assisted reproductive techniques were recorded as a positive or a negative response and analyzed.

\section{Results}

The study population (Table 1) included a total of 492 babies of whom 256 were male (52.03\%) and 236 were females (47.96\%). Of these 492 babies, 458 (93.08\%) were naturally conceived (nonART) and 34 (6.91\%) were conceived with assisted reproductive techniques (ART). Of those naturally conceived 237 (51\%) were male and $221(47.05 \%)$ were females. The number of twins and triplets was unarguably higher in the ART group $67 \%$ twins and $17 \%$ triplets) as compared to the naturally conceived group of cases (18\% twins and $6 \%$ triplets). The number of singleton pregnancies was remarkably low in the ART group (14\%) as compared to $74 \%$ in the other group. The mean age at first ROP screening was lower in the ART group as compared to the non-ART group (4 weeks vs 4.66 weeks) though not significant. $32 \%$ of cases in the ART group developed ROP while only $22 \%$ of those conceived naturally developed ROP [after continuity correction OR - 1.72 (95\% CI: $0.82,3.61$ ) with p-value $>0.05]$. The proportion of cases of ROP who reached the threshold criteria for treatment in the ART group (15.5\%) was higher than the other group where only $17.8 \%$ cases were advised treatment for ROP [after continuity correction OR 5.33 (95\% CI: 1.54, 18.47) with p-value < 0.05]. The proportion of cases who developed aggressive posterior ROP and underwent intravitreal injection of Anti-VEGF agent were also higher in the ART group $9 \%$ as compared to $1.9 \%$ in the non ART group [after continuity correction OR - 0.56 (95\% CI: 0.06, 5.23) with p-value > 0.05].

\begin{tabular}{|c|c|c|c|}
\hline & ALL & $\begin{array}{c}\text { Natural } \\
\text { conception }\end{array}$ & ART \\
\hline $\begin{array}{l}\text { Total number of } \\
\text { Patients }\end{array}$ & 492 & 458 & 34 \\
\hline $\begin{array}{l}\text { Mean Birth weight } \\
\text { (gm) (SD) }\end{array}$ & $\begin{array}{c}1572.7 \mathrm{gm} \\
(470.2)\end{array}$ & $\begin{array}{l}1570.0 \\
(472.0)\end{array}$ & $\begin{array}{l}1525.33 \\
(502.2)\end{array}$ \\
\hline $\begin{array}{l}\text { Mean Gestational } \\
\text { age (wks) (SD) }\end{array}$ & $32.14(3.04)$ & $32.14(3.04)$ & $31.97(3.02)$ \\
\hline \multicolumn{4}{|l|}{ Gender } \\
\hline Male & $256(52.03 \%)$ & 237 (51\%) & $18(52.94 \%)$ \\
\hline Female & $236(47.96 \%)$ & $221(48.25 \%)$ & $16(47.05 \%)$ \\
\hline \multicolumn{4}{|l|}{ Multiple births } \\
\hline Singleton & $348(70.73 \%)$ & $343(74.08 \%)$ & $5(14.70 \%)$ \\
\hline Twins & $109(22.15 \%)$ & $86(18.77 \%)$ & $23(67.64 \%)$ \\
\hline Triplets & $35(7.11 \%)$ & $29(6.33 \%)$ & $6(17.64 \%)$ \\
\hline $\begin{array}{l}\text { Mean Age at first } \\
\text { screening }\end{array}$ & $\begin{array}{c}4.81 \pm 1.93 \\
\text { wks }\end{array}$ & $\begin{array}{c}4.66 \pm 1.63 \\
\text { wks }\end{array}$ & $4.00 \pm 1.74$ \\
\hline $\begin{array}{l}\text { No. of cases who } \\
\text { developed ROP }\end{array}$ & $112(22.76 \%)$ & $101(22.05 \%)$ & $11(32.35 \%)$ \\
\hline $\begin{array}{l}\text { No of cases who } \\
\text { needed treatment }\end{array}$ & $\begin{array}{c}24 \text { of } 112 \\
(21.4 \%)\end{array}$ & $\begin{array}{l}18 \text { of } 101 \\
(17.82 \%)\end{array}$ & $\begin{array}{c}6 \text { of } \\
11(54.54 \%)\end{array}$ \\
\hline Underwent laser & 21 & 16 & 5 \\
\hline $\begin{array}{l}\text { No. of cases with } \\
\text { AP-ROP who } \\
\text { Underwent } \\
\text { intravitreal } \\
\text { Anti-VEGF inj. }\end{array}$ & $\begin{array}{c}3 \text { of } 112 \\
(2.6 \%)\end{array}$ & $\begin{array}{c}2 \text { of } 101 \\
(1.9 \%)\end{array}$ & 1 of $11(9 \%)$ \\
\hline
\end{tabular}

Table 1: Patient characteristics. 


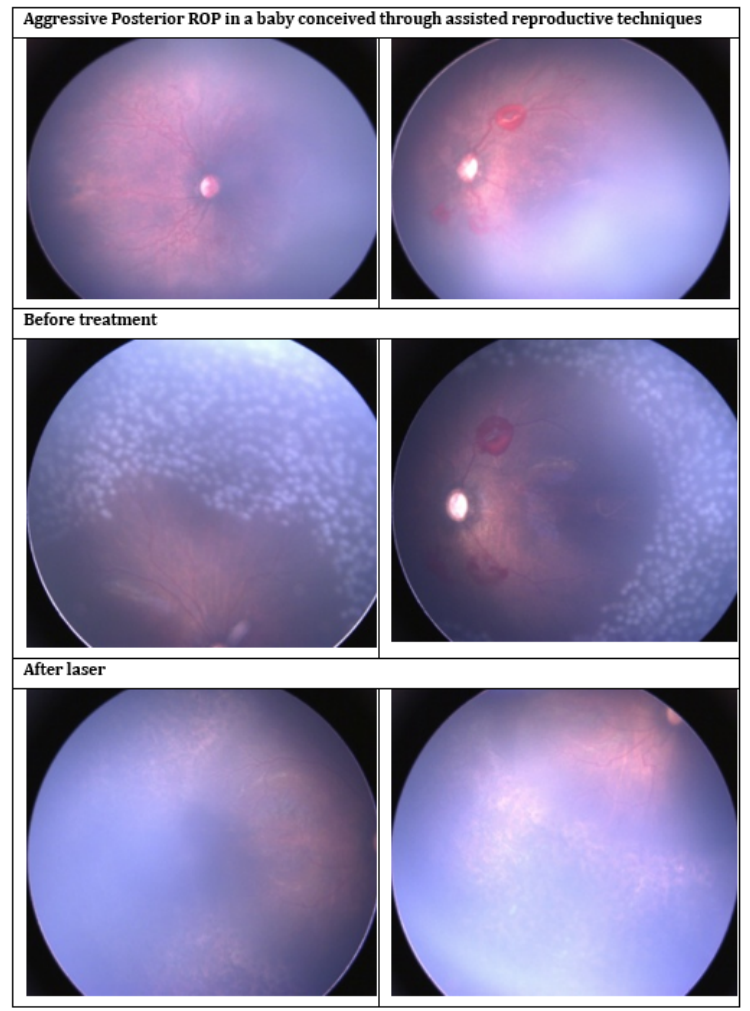

\section{Discussion}

With increasing adoption of ART and more premature babies being born, the possibility of increased ROP especially severe ROP remains a major concern. It is therefore necessary to discover the relationship between these two aspects. Watts P., et al. found positive association between the development of ROP and assisted reproductive techniques [12]. The relationship between ROP and assisted reproductive techniques however have been inconclusive in the study by Friling., et al. [11]. Chan., et al. observed a modestly significant increase in mean birth weight of infants born through assisted reproductive techniques than those through natural conception [14]. Contrary to this finding we found that ART babies have a lower mean birth weight than the naturally conceived group. Assisted reproductive techniques have been associated with multiple gestations in previous studies [15], a finding consistent in our study also with a higher number of multiple pregnancies (twins and triplets) observed in the ART group. Chan., et al. found that it were the multiplets who required laser more [14]. Contrary to our findings, Friling., et al. found singletons to be more likely to have severe ROP. Development of ROP was significant in the ART group with nearly $1 / 3^{\text {rd }}$ babies developing ROP compared to those conceived naturally. Over $1 / 2$ the ART babies developed threshold ROP requiring treatment significantly more than those born of natural conception. The proportion of babies who developed aggressive posterior ROP and underwent intravitreal injection of Anti-VEGF agent were also higher in the ART group compared to the non ART group. These findings suggest that babies born through assisted conception are more likely to develop more severe form of ROP and are more likely to be candidates in need of laser and Anti-VEGF injections. The fact that the mean age and gestational age at birth did not vary much between the two groups in our study may suggest that use of assisted reproductive techniques could be an independent risk factor for developing severe ROP. In 2018, Trifonova., et al. published a systematic review to discuss the relationship between ART and ROP. Consistent with our findings, the results showed that though insignificant, ROP was observed which was more frequent in ART babies.

As this was a retrospective analysis of data, some confounding factors like maternal age, presence of pre-eclamsia/eclampsia and gestational hypertension in the mothers, sepsis, intraventricular hemorrhage (IVH), mechanical ventilation, oxygen therapy and blood transfusion were not analysed. However vital neonatal factors like birth weight and gestational age did not vary significantly between the groups.

There were several limitations in this study. First, the role of other confounding variables have not been excluded entirely. Neonatal/ maternal factors and variability and complexity of ART treatment could render the specification of individual factors extremely challenging, which brings some bias to the study. Second, the biological mechanism underlying the relationship between using ART and the risk of ROP in offspring cannot be specified in the current study. Therefore, more studies directly comparing the relationship between ART and ROP should be included in future reviews. Besides, the subtype of ART within studies should also be further distinguished and studied.

However, this analysis highlights an important observation relevant to treating physicians. Doctors should inform couples the underlying risks of ROP occurrence (especially stage 3ROP) who decide to adopt the IVF technology. Also, pediatric ophthalmologists should pay more attention to those IVF babies when performing ROP screening. More important, to avoid serious visual complications, neonatologists and paediatricians may advise couples who have babies with IVF to conduct ROP screening routinely. 


\section{Conclusion}

This study found that neonates born through assisted conception were more likely to develop severe form of disease and these cases make up a considerable proportion of the ROP babies who need treatment. Hence increased vigilance is required while treating couples with ART ensuring adequate screening practices for babies conceived by assisted conception for ROP. With the demand for infertility treatment and use of assisted conception increasing, it can only be expected that this number will increase in future.

\section{Bibliography}

1. Gogate P., et al. "Severe visual impairment and blindness in infants: causes and opportunities for control". Middle East African Journal of Ophthalmology 18 (2011): 109-114.

2. Chang JY., et al. "Decreasing trends of neonatal and infant mortality rates in Korea: compared with Japan, USA, and OECD nations". Journal of Korean Medical Science 26.9 (2011): 11151123.

3. Augestad LB., et al. "Braille use among Norwegian children from 1967 to 2007: trends in the underlying causes". Acta Ophthalmologica 90.5 (2012): 428-434.

4. Blencowe H., et al. "National, regional, and worldwide estimates of preterm birth rates in the year 2010 with time trends since 1990 for selected countries: a systematic analysis and implications". Lancet 379 (2012): 2162-2172.

5. Karna P., et al. "Retinopathy of prematurity and risk factors: A prospective cohort study". BMC Pediatrics 5 (2005): 18.

6. Azad R. "Prevention of blindness due to retinopathy of prematurity: A national movement". Indian Journal of Pediatrics 81 (2014): 1373-1375.

7. Puri S., et al. "Screening of retinopathy of prematurity: A neglected public health issue". The Annals of Medical and Health Science Research 4 (2014): S65-66.

8. Malhotra N., et al. "Assisted reproductive technology in India: A 3 year retrospective data analysis". Journal of Human Reproductive Sciences 6.4 (2013): 235-240.

9. Minasian M and Fielder A. "IVF babies with severe retinopathy of prematurity at higher gestational age and birth weight: Implications of changing screening criteria”. British Journal of Ophthalmology 89.8 (2005): 1066.
10. McKibbin M and Dabbs TR. "Assisted conception and retinopathy of prematurity". Eye 10.4 (1996): 476-478.

11. Friling R., et al. "Retinopathy of prematurity in assisted versus natural conception and singlet on versus multiple births". Ophthalmology 114.2 (2007): 321-324.

12. Watts $P$ and Adams GG. "In vitro fertilisation and stage 3 retinopathy of prematurity”. Eye 14.3 (2000): 330-333.

13. Funnell CL and Dabbs TR. "Assisted conception and retinopathy of prematurity: 8-year follow-up study". Eye 21.3 (2007): 383-386.

14. Chan RP., et al. "Association between assisted reproductive technology and advanced retinopathy of prematurity". Clinical Ophthalmology 4 (2010): 1385-1390.

15. Saunders RA., et al. "Racial variation in retinopathy of prematurity. The Cryotherapy for Retinopathy of Prematurity Cooperative Group". Archives of Ophthalmology 115.5 (1997): 604608.

16. Trifonova K., et al. "Artificial reproductive technology - a risk factor for retinopathy of prematurity". Open Access Macedonian Journal of Medical Sciences 11.6 (2018): 2245-2249.

\section{Volume 4 Issue 9 September 2021 (C) All rights are reserved by Sameer I., et al.}

